\title{
Article \\ Extra-Heavy Crude Oil Degradation by Alternaria sp. Isolated from Deep-Sea Sediments of the Gulf of Mexico
}

\author{
Lucia Romero-Hernández ${ }^{1}$, Patricia Velez ${ }^{2} \mathbb{D}$, Itandehui Betanzo-Gutiérrez ${ }^{3}$, María Dolores Camacho-López ${ }^{1}$, \\ Rafael Vázquez-Duhalt ${ }^{3}$ and Meritxell Riquelme ${ }^{1, *(D)}$
}

1 Departamento de Microbiología, Centro de Investigación Científica y de Educación Superior de Ensenada (CICESE), Ensenada, Baja California 22860, Mexico; lromero@cicese.edu.mx (L.R.-H.); mcamacho@cicese.edu.mx (M.D.C.-L.)

2 Departamento de Botánica, Instituto de Biología, Universidad Nacional Autónoma de México, Ciudad de México 04510, Mexico; pvelez@ib.unam.mx

3 Centro de Nanociencias y Nanotecnología (CNyN), Universidad Nacional Autónoma de México (UNAM), Baja California 22860, Mexico; ibetanzo@cigom.org (I.B.-G.); rvd@cnyn.unam.mx (R.V.-D.)

* Correspondence: riquelme@cicese.mx

Citation: Romero-Hernández, L.; Velez, P.; Betanzo-Gutiérrez, I.; Camacho-López, M.D.;

Vázquez-Duhalt, R.; Riquelme, M. Extra-Heavy Crude Oil Degradation by Alternaria sp. Isolated from Deep-Sea Sediments of the Gulf of Mexico. Appl. Sci. 2021, 11, 6090. https://doi.org/10.3390/ app11136090

Academic Editors: Anna Poli and Valeria Prigione

Received: 20 May 2021

Accepted: 23 June 2021

Published: 30 June 2021

Publisher's Note: MDPI stays neutral with regard to jurisdictional claims in published maps and institutional affiliations.

Copyright: (c) 2021 by the authors. Licensee MDPI, Basel, Switzerland. This article is an open access article distributed under the terms and conditions of the Creative Commons Attribution (CC BY) license (https:/ / creativecommons.org/licenses/by/ $4.0 /)$.
Abstract: The Gulf of Mexico (GoM) is an important source of oil for the United States and Mexico. There has been growing interest, particularly after the Deepwater Horizon oil spill, in characterizing the fungal diversity of the GoM and identifying isolates for use in the bioremediation of petroleum in the event of another spill. Most studies have focused on light crude oil bioremediation processes, while heavy crude oil (HCO) and extra-heavy crude oil (EHCO) have been largely ignored. In this work, we evaluated the ability of fungal isolates obtained from deep-sea sediments of the Mexican economic exclusive zone (EEZ) of the GoM to degrade HCO (16-20 API) and EHCO (7-10 $\left.0^{\circ} \mathrm{API}\right)$. Alternaria sp., Penicillium spp., and Stemphylium sp. grew with $\mathrm{HCO}$ as the sole carbon source. Remarkably, Alternaria sp. was the only isolate able to grow with EHCO as the sole carbon source, degrading up to $25.6 \%$ of the total $\mathrm{EHCO}$ and $91.3 \%$ of the aromatic fraction, as demonstrated by gas chromatography analysis of the saturate, aromatic, and polar fractions. These findings proved to be significant, identifying Alternaria sp. as one of the few fungi reported so far capable of degrading untreated EHCO and as a suitable candidate for bioremediation of EHCO in future studies.

Keywords: heavy crude oil; mycodegradation; deep-sea fungi; bioremediation; fungal isolation

\section{Introduction}

Crude oil has become the most important source of energy for humankind. It has been estimated that, by 2035, it will supply more than one-third of the total global energy demands [1,2]. Light crude oil has been the primary option to produce refined products for everyday use, such as gasoline, diesel, and kerosene, among many others [3,4]. However, reserves of conventional light crude oil are rapidly being depleted all around the world, while, at the same time, the demand for fossil fuel is continually increasing as a result of human population growth and economic development [5]. Alternative green energy sources with lower carbon footprints (e.g., solar and eolic) have improved to become economically viable, but they are nonetheless insufficient to supply the increasing energy demand [6]. Therefore, the exploitation of unconventional petroleum fuel resources (tar sands and extra-heavy oil deposits) might emerge as an alternative source of fossil fuel in the next decades [7]. Heavy and extra-heavy crude oil (HCO and EHCO, respectively) make up $70 \%$ of the world's oil reserves [7]. However, their high content in resins and asphaltenes represents a significant challenge for its extraction, production, and refinement, in addition to the associated risk of accidental spills. Additionally, polycyclic aromatic hydrocarbons (PHAs) are also present in a significant ratio in HCO and EHCO. These fractions are one of the major concerns in oil spills, given their resistance to microbial degradation [8], long-term persistence in the environment [9], and ecotoxicity [10-12]. 
Bioremediation is a well-documented option that involves applying microorganisms to neutralize petroleum in the environment [13]. It targets those microbes capable of synthesizing enzymes that cleave $\mathrm{C}: \mathrm{H}$ bounds from petroleum hydrocarbons and transforms them into harmless and less persistent molecules [14]. However, while the microbial biodegradation of hydrocarbons and crude oils has been widely studied for decades, most studies have focused on light crude oils and their low molecular weight fractions or purified components [15]. In contrast, the microbial biodegradation of HCO and EHCO, particularly by fungi, has been scarcely studied.

Only a few fungal strains isolated from extreme environments are able to degrade asphaltenes and high molecular weight PAHs [16]. Aspergillus fischeri (previously Neosartorya fischeri), isolated from an asphalt lake in Venezuela, was the first microorganism able to grow using purified asphaltenes as the sole carbon source [17]. This fungus set a unique precedent demonstrating its remarkable ability to degrade extremely complex hydrocarbon molecules, especially high molecular weight PHAs [18]. The extremophilic fungus Pestalotiopsis palmarum BM-04 isolated from an asphalt lake in Venezuela synthesizes oxidative exoenzymes that catalyze the biotransformation of maltenes, asphaltenes, and the petroporphyrins-rich fraction of biotreated EHCO [19]. Paecilomyces variotii, Fusarium decemcellulare, Candida palmioleophila, and Pichia guilliermondii, isolated from a petroleum activity site in Indonesia, were able to degrade 10-15\% of resins and asphaltenes using BAL150 light crude oil as the sole carbon source [20]. A chloroperoxidase obtained from Caldariomyces fumago transformed the porphyrin-free asphaltene fraction recovered from Maya HCO, reducing it by 24\% [21]. Furthermore, Daedaleopsis sp., isolated from a forest in Iran, showed biodegradation of $38 \%$ of the asphaltene and aromatic fractions of HCO [22].

The Gulf of Mexico (GoM) is rich in petroleum reservoirs, and since 2017, their ultradeep waters have been exploited to obtain crude oil [23]. Therefore, it represents an ideal prospecting source to isolate indigenous fungal strains adapted to deep-sea conditions and capable of degrading crude oil. In a previous study, the fungal taxa Aureobasidium sp., Penicillium brevicompactum, Penicillium sp., Phialocephala sp., and Cladosporium sp. isolated from sediments of the Mexican economic exclusive zone (EEZ) of the GoM were identified as able to metabolize alkane and alkene, long-chain hydrocarbons poorly degraded by bacteria, as the sole carbon sources [24]. Furthermore, the RNA-seq expression analysis of Penicillium sp. cultured with hexadecane or 1-hexadecene showed the upregulation of genes involved in transmembrane transport, metabolism of six-carbon carbohydrates, and nitric oxide pathways [24].

In this study, we set out to identify culturable strains of marine fungi native to the seafloor of the Mexican EEZ of the GoM with the ability to degrade untreated EHCO. Alternaria sp. was the only isolate identified as capable of growing using EHCO as the sole carbon source and degrading a significant portion of the whole EHCO.

\section{Materials and Methods}

\subsection{Sampling}

The deep-sea sediment samples were collected from twenty-four stations located in Coatzacoalcos (also known as the Salina basin) and in the Perdido fold belt in the Mexican EEZ of the GoM (Figure 1). Samples were collected employing a Reineck box corer at different depths (Table S1) during the Metagenomics (MET-II) campaign that took place in 2017 onboard the research vessel Justo Sierra (UNAM). Subsamples were taken from the first $20 \mathrm{~cm}$ of the sediment collected with the box corer using pre-cut $50-\mathrm{mL}$ sterile syringes. Syringes were sealed with plastic film and stored at $4{ }^{\circ} \mathrm{C}$ and transported to the laboratory for processing. 


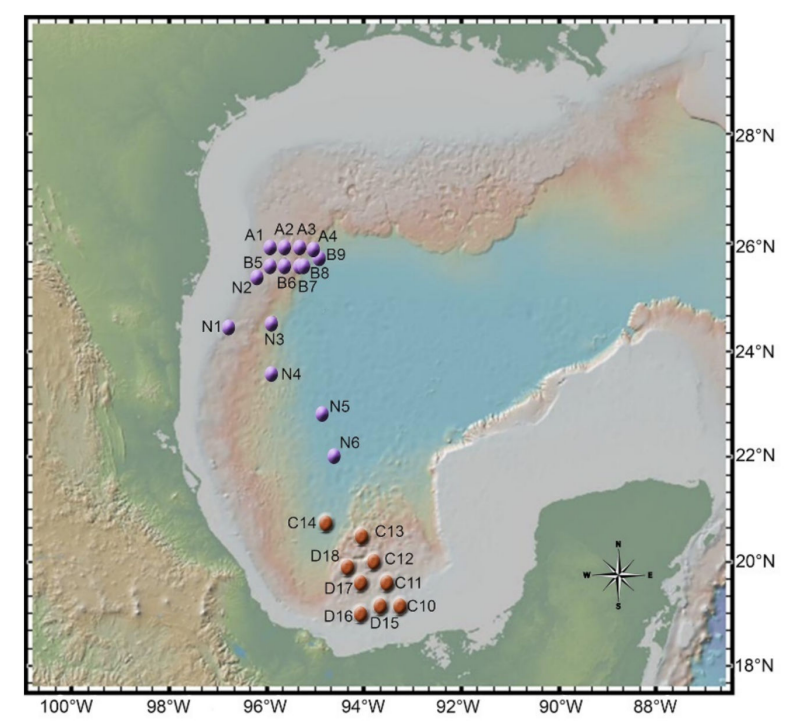

Figure 1. Localization of twenty-four sampled stations in the Gulf of Mexico, nine in Coatzacoalcos, also known as the Salina basin (orange dots), and fifteen in the Perdido fold belt region (purple dots).

\subsection{Fungal Isolation and Identification}

Sediment samples were processed as described previously [24]. Briefly, fungi were initially isolated in a five-fold diluted medium. For maintenance, fungal isolates were grown on a potato dextrose agar (PDA) medium. Colony morphology and pigmentation were registered using a Nikon D3100 Digital Camera (Nikon Inc., Tokyo, Japan). In addition, to analyze the microscopic characteristics, including the hyphal shape, morphology, size of spores, and conidiogenous cells, fungi were grown on water agar $(1.5 \%$ agar). Samples were processed by using the inverted block technique [25]. Imaging was carried out by DIC (Differential Interference Contrast) on a Nikon eclipse Ti-E microscope with an oil $60 \times$ objective. Macroscopic and microscopic characteristics, as well as Taxonomic Keys [26] and the data available in MycoBank (http:/ / www.mycobank.org/) (accessed on 9 December 2020), were considered to reach genus-level identification. Total genomic DNA was extracted from axenic isolates with the DNeasy Plant Mini Kit (Qiagen). Sequencebased taxonomic verification was achieved through phylogenetic analyses [27] using: (1) the internal transcribed spacer (ITS) region of the nuclear ribosomal DNA ITS1-5.8 rDNA using the primer set ITS1F (5-CTTGGTCATTTAGAGGAAGTAA-3) [28] and ITS4 (5-TCCTCCGCTTATTGATATGC-3) [29], (2) the 18S rRNA gene using primer set NS1 (5GTAGTCATATGCTTGTCTC-3) and NS4 (5-CTTCCGTCAATTCCTTTAAG-3) [30], and (3) the $\beta$-tubulin gene (benA) with primer set Bt2A (5-GGTAACCAAATCGGTGCTGCTTTC-3) and Bt2b (5-ACCCTCAGTGTAGTGACCCTTGGC-3) [31] and with degenerate primers LR1 (5-RRCRACAARTTCGTGCCCCG-3) and LR2 (5-AGTGAACTGGTCACCYACAC-3), newly designed to amplify another region of the $\beta$-tubulin gene downstream of the region amplified with primer set Bt2A and Bt2b for cases in which that primer set did not work. The PCR products were purified using a QIAquick Gel Extraction Kit and commercially sequenced by Eton Bioscience, Inc., San Diego, CA, USA.

Consensus sequences were generated using Consed v29.0 [32-34] and compared to the GenBank Database through a BLAST search (http:/ / www.ncbi.nlm.nih.gov / BLAST) (accessed on 9 December 2020) using the MegaBLAST algorithm to retrieve the reference sequences for the phylogenetic analyses. Only hit sequences with a minimum coverage of $98 \%$ were considered for the analyses, pondering accessions associated with vouchers and type material (Table S2). Uncultured/environmental sample sequences were not considered for the analyses. Sequences were aligned with the software UGENE v36.1 [35] using MUSCLE [36]. Phylogenetic trees were inferred by MEGA X [37,38] with the Maximum Likelihood (ML) algorithm, a bootstrap test of 1000 replications, and the K2+I (ITS and $18 \mathrm{~S})$ and $\mathrm{K} 2+\mathrm{G}$ and $\mathrm{HKY}+\mathrm{G}$ ( $\beta$-tubulin benA and LR1-LR2, respectively) models of nu- 
cleotide substitution [39]. Initial trees for the heuristic search were obtained automatically by applying Neighbor-Joining and BioNJ algorithms to a matrix of pairwise distances estimated using the Maximum Composite Likelihood (MCL) approach and then selecting the topology with a superior log likelihood value. The sequences are available in GenBank under the accession numbers MW412481-MW412485 for the 18S, MW412490-MW412494 for the ITS, and MZ392424-MZ392428 for the $\beta$-tubulin sequences (Table S3).

\subsection{Growth with Crude Oil as a Sole Source of Carbon}

Fungal conidia were cultured using crude oil as a sole carbon source to evaluate if oil metabolization occurred. Fungal strains were grown on PDA plates and incubated for five days at $30^{\circ} \mathrm{C}$ to obtain conidia. Even though the strains could grow at room temperature, at $30^{\circ} \mathrm{C}$, an accelerated growth was observed. Conidia were recovered from the PDA plates using distilled sterile water, separated from mycelium through filtration, and washed twice with sterile distilled water. Conidia were counted using a Neubauer Chamber. Flasks containing $50 \mathrm{~mL}$ of modified Czapek minimal medium without a carbon source (4-g $\mathrm{NaNO}_{3}, 2$-g $\mathrm{K}_{2} \mathrm{HPO}_{4}, 1$-g $\mathrm{MgSO}_{4} \bullet 7 \mathrm{H}_{2} \mathrm{O}$, 1-g KCl, 0.02-g FeSO $4{ }_{4} \bullet 7 \mathrm{H}_{2} \mathrm{O}$, 32-g sea salt, and $0.5 \mathrm{~mL}$ of trace mineral solution) [40] were inoculated with $2 \times 10^{7}$ conidia. The flasks were supplemented with $0.5 \%$ of three different types of petroleum according to the American Petroleum Institute (API) classification: light crude oil $\left(40^{\circ}\right.$ API from the well Xux in Tabasco, Mexico), heavy (16-20 API from the field Bacal in Tabasco), or extra-heavy (7-10 API from the well Ayatsil-Telek in Campeche, Mexico) crude oil as a sole source of carbon. The cultures were incubated at $30^{\circ} \mathrm{C}$ under $150 \mathrm{rpm}$ up to a month with weekly revisions.

\subsection{Microscopic Analysis}

To assess the ability of conidia to germinate using crude oil as a unique carbon source, hyphal development was observed by Differential Interference Contrast (DIC) microscopy using a Nikon Inverted Microscope Eclipse Ti-E with a $40 \times 0.95$ objective. Mycelial samples from each culture were taken from the petroleum-culture medium interface with a sterile bacteriological loop. The sample was spread onto a microscope slide with a drop of water.

Since Alternaria sp. was the only strain that displayed visible growth on the EHCO added to the modified Czapek medium, the samples were analyzed by Scanning Electron Microscopy (SEM) to image the mycelium-petroleum interface further. After three weeks, when mycelium was visible, the medium was poured off. A small portion of the mix containing petroleum and fungal biomass was fixed for two hours with $50 \mathrm{~mL}$ of a solution containing paraformaldehyde $1 \%$, glutaraldehyde $2 \%$, and potassium buffer $0.1 \mathrm{M}$ $\left(\mathrm{K}_{2} \mathrm{HPO}_{4} 1 \mathrm{M}\right.$ and $\left.\mathrm{KH}_{2} \mathrm{PO}_{4} 1 \mathrm{M}, \mathrm{pH} 6.8\right)$. The solution was removed by decantation, and the sample was covered with $2 \%$ osmium tetroxide and incubated for one hour. Finally, alcohol at different concentrations $(25 \%, 50 \%, 75 \%$, and $100 \%)$ was employed to fix and dehydrate the sample, which was imaged on a Hitachi SU3500 SEM.

\subsection{Fungal Growth Quantification}

To corroborate the mycelial growth of Alternaria sp. with EHCO as a unique carbon source, the protein concentration was quantified. The fungal cultures were incubated for a month at $30{ }^{\circ} \mathrm{C}$ under $150 \mathrm{rpm}$. Next, $20 \mathrm{~mL}$ of toluene were added to separate the mycelium from the EHCO. The culture was shaken vigorously and transferred to a centrifuge tube. The mixture was centrifuged at 15,000 rpm for $10 \mathrm{~min}$, and the organic upper layer containing the remaining oil was removed. The pellet containing the fungal biomass was recovered by filtration with a vacuum pump through a Whatman Grade 1 Qualitative Filter Paper $10.25 \mathrm{~mm}$. The mycelium was ground in a mortar with liquid nitrogen; mixed with $1 \mathrm{~mL}$ of lysis buffer (1-M Tris $\mathrm{pH} 7.4,2-\mathrm{M} \mathrm{KCl}, 1-\mathrm{M} \mathrm{MgCl}_{2}$, Triton X100, and one tablet of Complete Mini Protease Inhibitor Cocktail, Roche, CDMX, Mexico); and maintained for $30 \mathrm{~min}$ at $4{ }^{\circ} \mathrm{C}$. After centrifugation at $12,000 \times g$ for $10 \mathrm{~min}$, the supernatant 
was collected to measure the total protein content of the lysate. Abiotic cultures (EHCO and modified Czapek minimal medium) and cultures without EHCO were used as controls, and all experiments were performed in independent triplicates. An independent samples $t$-test was conducted to compare the $\mathrm{mg} / \mathrm{L}$ of protein in control and treatment cultures. A Bio-Rad Protein Assay was used to quantify the protein content, and a BSA standard curve was included.

When all the strains were tested in the early stages of this project, Penicillium spp. were grown under different concentrations of light crude oil $(0.25,0.5 \%$, and $0.75 \% v / v)$ as the sole carbon source to determine at which concentration they produced more biomass. It was unnecessary to add toluene to separate the mycelium from the oil, because there was no strong attachment between them, and the mycelium was easily recovered through filtration. Abiotic cultures (light crude oil and modified Czapek minimal medium) and cultures without light crude oil were used as controls, and all experiments were performed in independent triplicates. A one-way between treatments ANOVA was conducted to compare the effect of petroleum at different concentrations. Post hoc comparisons were conducted using Turkey's honestly significant difference (HSD).

\subsection{Liquid-Liquid Extraction}

Flasks containing $50 \mathrm{~mL}$ of modified Czapek medium supplemented with $0.5 \%$ w/v of EHCO (7-10 API) as unique carbon sources and inoculated with $2 \times 10^{7}$ conidia of Alternaria sp. were incubated at $30^{\circ} \mathrm{C}$ and stirred at $150 \mathrm{rpm}$ for a month. The remaining oil was extracted to perform the gas chromatography analysis. The medium was acidified with $\mathrm{HCl}$ and extracted with $10 \mathrm{~mL}$ of dichloromethane three times. The organic extract was recovered, dehydrated on an anhydrous $\mathrm{Na}_{2} \mathrm{SO}_{4}$ column, and dried on a rotary evaporator under $0.79 \mathrm{~atm}$.

\subsection{SAP Analysis}

To analyze the percentage of degradation of the different fractions of EHCO by Alternaria sp., the crude oil was fractionated by a modified SARA (saturates, aromatics, resins, and asphaltenes) standard method (ASTM D2007). The modification consisted in obtaining the resins and asphaltenes components together in one fraction only. As a result, the saturates, aromatics, and polar (resins and asphaltenes) fractions were obtained (SAP). All the fractions were analyzed by gas chromatography. The solvents used were $\mathrm{n}$-hexane to separate the saturates, toluene for the aromatics, and a mixture of methanol and dichloromethane (50:50) for resins and asphaltenes. The separation was made through a silica column, and three fractions were obtained according to the increasing polarity of the solvents. The fractions were evaporated on a rotary evaporator and analyzed on an Agilent 7820A Gas Chromatographer with a Zebron Inferno $20 \mathrm{~m} \times 0.18 \mathrm{~mm} \times 0.18 \mu \mathrm{m}$ column (Phenomenex, Los Angeles, CA, USA), according to the EPA-8015 method (US EPA). The Zebron Inferno column, with a high temperature range, allowed to analyze the volatile asphaltenes. The total petroleum hydrocarbons (TPH) were quantified as the response of the flame ionization detector (FID). The GC program started at $50{ }^{\circ} \mathrm{C}(2 \mathrm{~min})$, followed by a temperature ramp of $10^{\circ} \mathrm{C} / \mathrm{min}$ at $375^{\circ} \mathrm{C}(5 \mathrm{~min})$. The spitless injector was set up at $360{ }^{\circ} \mathrm{C}$ and the detector at $400^{\circ} \mathrm{C}$. Helium was used as carrier gas at a constant flow of $0.9 \mathrm{~mL} / \mathrm{min}$.

\section{Results}

\subsection{All Fungal Isolates Recovered belonged to the Ascomycota}

Twenty-seven fungal isolates were obtained from the twenty-four sites of the GoM. These were clustered into five morphotypes based on macroscopic and microscopic morphological features (Figure 2). Based on the phylogenetic analysis of the sequenced ITS region, $18 \mathrm{~S}$ rRNA gene, and $\beta$-tubulin gene, we unequivocally identified Cladosporium halotolerans to the species level ( $\geq 99 \%$ beta-tubulin sequence similarity and supported by $97 \%$ bootstrap value) and four isolates to the genus level (Table S3 and Figure 3). All the 
isolates belonged to the phylum Ascomycota within the Aspergillaceae, Cladosporiaceae, and Pleosporaceae families (Figure 3). Alternaria sp. was isolated from the Perdido region (station N2; ID:4), whereas C. halotolerans (station C11; ID:1), Penicillium sp. 1 (station D16; ID:5), Penicillium sp. 2 (station C11; ID:6), and Stemphylium sp. (station C12; ID:3) were isolated from the Coatzacoalcos region (Table S3).

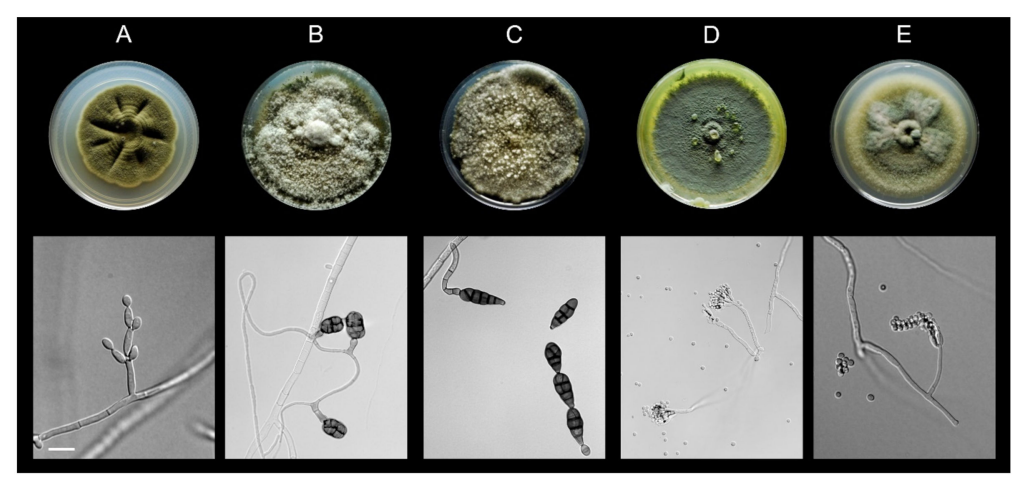

Figure 2. Macromorphology and micromorphology of the fungal isolates recovered from deep-sea sediment samples evaluated for their capacity to degrade petroleum. Top row: colony morphology of strains grown on Petri dishes containing potato dextrose agar medium. Bottom row: conidiophores and conidia of the fungal strains imaged by Differential Interference Contrast microscopy. Scale bar $=10 \mu \mathrm{m}$. (A) Cladosporium halotolerans, (B) Stemphylium sp., (C) Alternaria sp., (D) Penicillium sp. 1, and (E) Penicillium sp. 2.

A

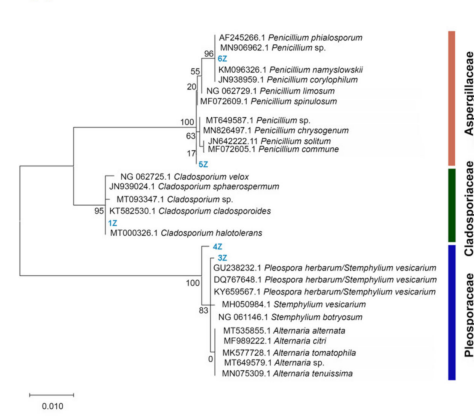

C

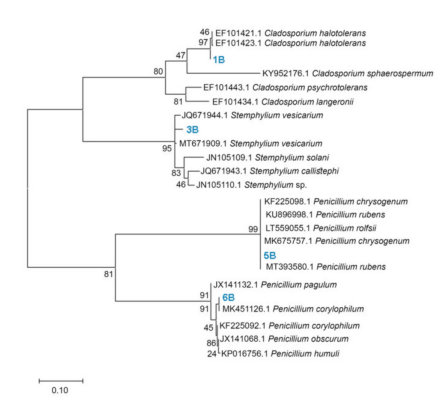

B

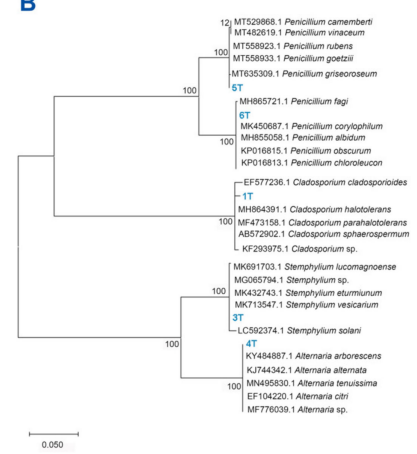

D

Figure 3. Evolutionary analysis by Maximum Likelihood method for (A) 18S, (B) ITS, and (C) $\beta$ tubulin. Bootstrap values are indicated above the branches. The phylogenetic position of deep-sea derived fungal sequences is denoted by blue color. The evolutionary history was inferred by using $\mathrm{K} 2+\mathrm{I}(\mathbf{A}, \mathbf{B}), \mathrm{K} 2+\mathrm{G}(\mathbf{C})$, and $\mathrm{HKY}+\mathrm{G}(\mathbf{D})$ substitution models. The tree with the highest log likelihood is shown. The initial tree for the heuristic search was obtained automatically by applying the NeighborJoin and BioNJ algorithms to a matrix of pairwise distances estimated using the Maximum Composite Likelihood (MCL) approach and then selecting the topology with the superior log likelihood value. The tree is drawn to scale, with the branch lengths measured in the number of substitutions per site. 


\subsection{Alternaria sp. Was Able to Grow with Extra-Heavy Crude Oil as the Sole Carbon Source}

The five fungal strains were assayed for growth at $0.5 \%$ of three different crude oils: light, heavy, or extra-heavy. All five strains were able to grow in light crude oil as the sole source of carbon. However, the heavier the crude oil was, the fewer strains were able to metabolize it. While four strains (Alternaria sp., Penicillium sp. 1, Penicillium sp. 2, and Stemphylium sp.) were able to grow in $\mathrm{HCO}$, only one, Alternaria sp., was able to grow in EHCO (Table 1).

Table 1. Growth of selected fungi in crude oils of different densities. The culture was carried out in $50 \mathrm{~mL}$ of modified Czapek minimal medium with $0.5 \%$ w/v of crude oil as the sole carbon source.

\begin{tabular}{|c|c|c|c|}
\hline \multirow[b]{2}{*}{ Identified Isolate } & \multicolumn{3}{|c|}{ Crude Oil Density } \\
\hline & $\begin{array}{c}\text { Light } \\
40^{\circ} \text { API }\end{array}$ & $\begin{array}{c}\text { Heavy } \\
16-20^{\circ} \text { API }\end{array}$ & $\begin{array}{c}\text { Extra-Heavy } \\
7-10^{\circ} \text { API }\end{array}$ \\
\hline Alternaria sp. & + & + & + \\
\hline $\begin{array}{l}\text { Cladosporium } \\
\text { halotolerans }\end{array}$ & + & - & - \\
\hline Penicillium sp. 1 & + & + & - \\
\hline Penicillium sp. 2 & + & + & - \\
\hline Stemphylium sp. & + & + & - \\
\hline
\end{tabular}

Under light microscopy, Alternaria sp., Penicillium sp. 1, and Penicillium sp. 2 hyphae were observed strongly adhered to the surface of the $\mathrm{HCO}$ (Figure $4 \mathrm{~A}-\mathrm{C}$ ). In contrast, Stemphylium sp. presented hyphal growth that did not adhere to the oil (Figure 4D). Regardless of how attached the hyphae were to the crude oil, the main purpose of this experiment was to confirm the presence of mycelium, and this was successfully achieved, as shown in the images obtained. When grown in EHCO, hyphae and conidia of Alternaria sp. also adhered to the sticky oil drops. By DIC microscopy, what appeared to be newly formed conidia at the tips of the hyphae were observed at the petroleum surface (Figure 5). By SEM, a dense mass of mycelium and conidia were observed as well growing at the surface of the petroleum (Figure 6).
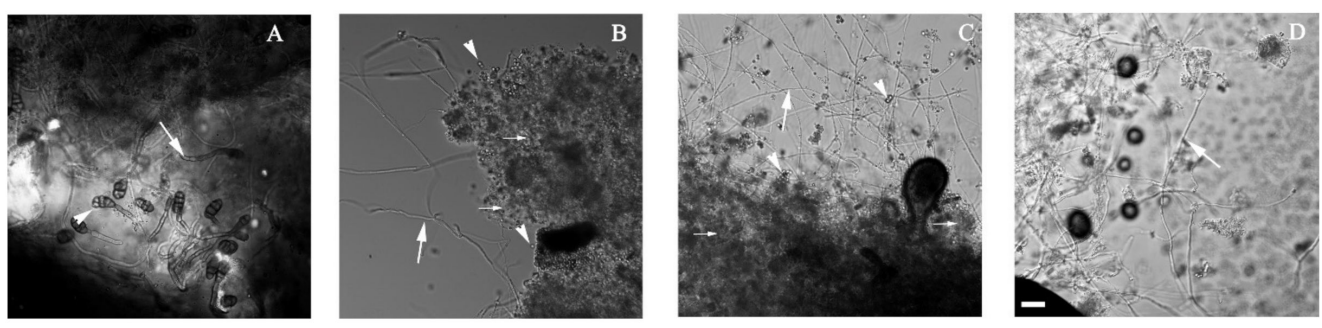

Figure 4. Differential interference contrast microscopy of fungal mycelia grown in Czapek minimal medium containing $0.5 \% w / v$ of heavy crude oil (16-20 API). (A) Alternaria sp. conidia (arrowheads) and mycelium (arrows) adhered to the oil after six days of incubation. (B) Penicillium sp. 1 hyphae (arrows) and conidia growth (arrowheads) after 24 days of incubation; salts from the Czapek minimal medium (small arrows) can be observed. (C) Penicillium sp. 2 mycelium (arrows) and conidia (arrowheads) embedded in salt (small arrows) and petroleum after 24 days of incubation. (D) Stemphylium sp. hyphae (arrows) with no attachment to petroleum after 27 days of incubation. Scale bar $=25 \mu \mathrm{m}$. 

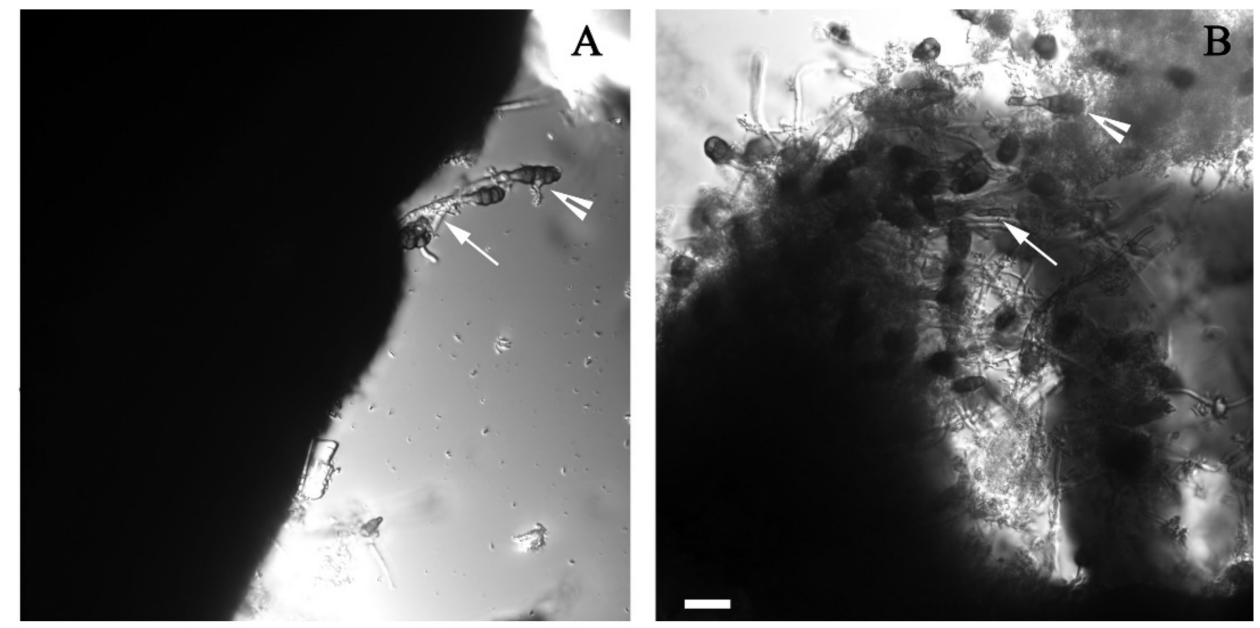

Figure 5. Differential interference contrast microscopy of Alternaria sp. grown in Czapek minimal medium containing $0.5 \%$ w/v of extra-heavy crude oil (7-10 $\mathrm{API}$ ). (A) Hyphae (arrow) and septate conidia (arrowhead) emerging from a dense mass of petroleum. (B) Mycelium (arrow) and conidia (arrowhead) with Czapek minimal medium salts and petroleum. Scale bar $=25 \mu \mathrm{m}$.
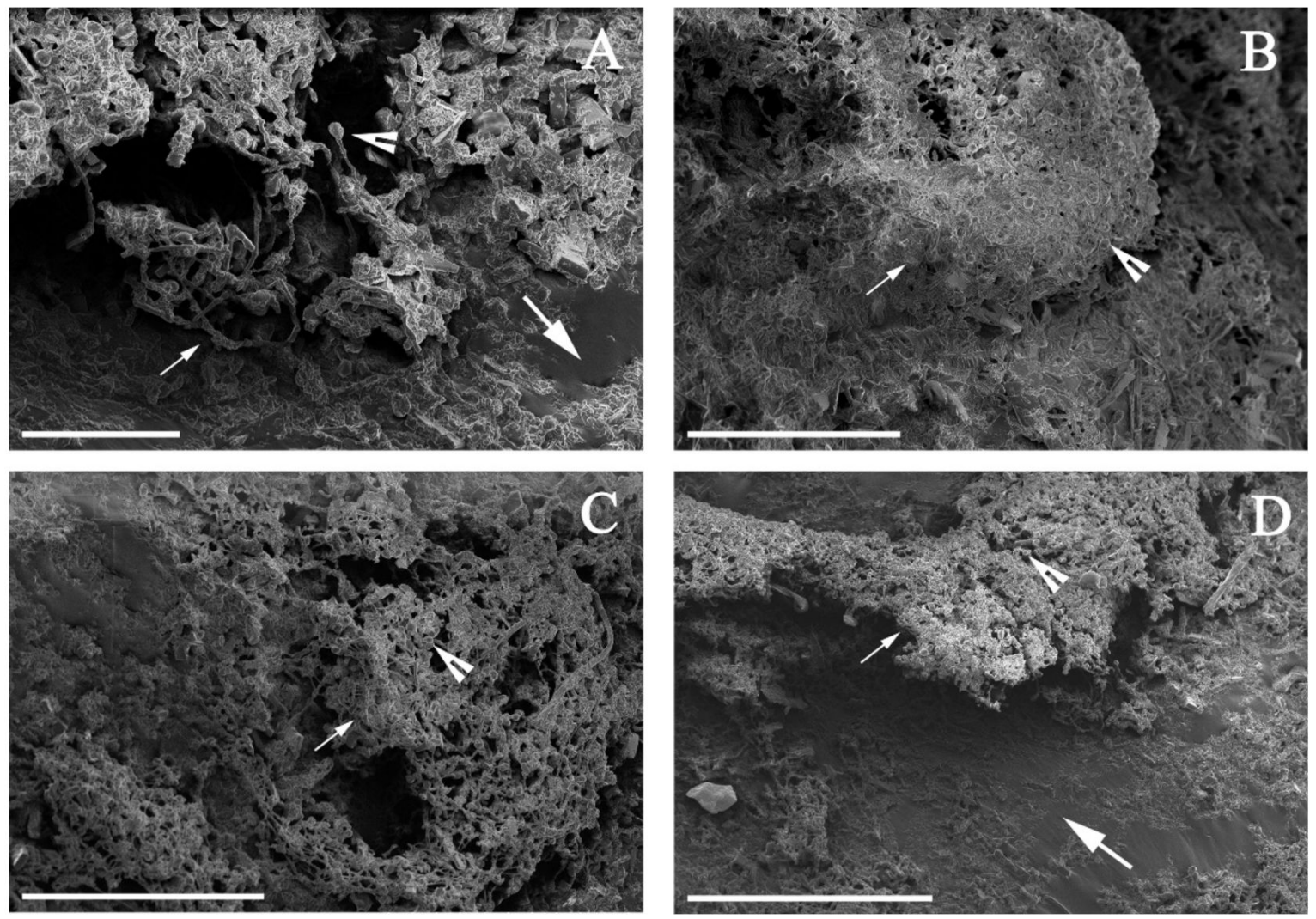

Figure 6. Scanning electron microscopy of Alternaria sp. grown in Czapek minimal medium containing $0.5 \%$ w/v of extraheavy crude oil (7-10 API). (A) Hyphae (small arrows), conidia (arrowheads), and smooth petroleum surface (arrows). Scale bar $=100 \mu \mathrm{m}$. (B) Mycelium (small arrows) and conidia (arrowheads). Scale bar $=200 \mu \mathrm{m}$. (C) Hyphae (small arrows) and conidia (arrowheads). Scale bar $=300 \mu \mathrm{m}$. (D) Mycelium (small arrows), conidia (arrowheads), and petroleum (arrows). Scale bar $=500 \mu \mathrm{m}$. In all images, the mycelium is in tight contact with the petroleum surface.

For both Penicillium spp., the maximum average amount of protein $(40.5 \pm 1.2 \mathrm{mg} / \mathrm{L}$ for Penicillium 1 and $46.0 \pm 13.7 \mathrm{mg} / \mathrm{L}$ for Penicillium 2) was obtained for the cultures amended with $0.75 \% v / v$ light crude oil (Figure S1). The protein concentration in Penicillium 
sp. 1 was significantly $(p=0.012)$ higher at the $0.75 \%(v / v)$ concentration than $0.25 \%(v / v)$ of the light crude oil. Whereas, for Penicillium sp. 2, no significant differences could be observed at the different concentrations of light crude oil ( $p=5.14$ ) (Figure S1).

To quantify protein concentration in the cultures of Alternaria sp. grown in Czapek minimal medium supplemented with $0.5 \% v / v$ EHCO, it was necessary to add toluene to separate the mycelium from the oil, because there was a strong attachment between them, and the mycelium could not be easily recovered through filtration. An average total protein increase of $7.04 \pm 0.20 \mathrm{mg} / \mathrm{L}$ was obtained for Alternaria spp. cultures that were grown for a month in Czapek minimal medium supplemented with $0.5 \%$ w $/ v$ EHC. That value was slightly higher, although not more significantly than the one obtained for the control cultures without EHCO $(5.9 \pm 0.32 \mathrm{mg} / \mathrm{L})(p=0.066)$.

\subsection{Alternaria sp. Mainly Metabolizes the Aromatic Components of the EHCO}

After 30 days of growth, EHCO degradation by Alternaria sp. was determined by gas chromatography in both whole EHCO and their fractions (Figure 7). The main components of the original EHCO corresponded to the aromatic fraction with $43.5 \%( \pm 10.8)$, followed by saturates with $35.5 \%( \pm 1.5)$ and the polar (resins-asphaltenes) fractions $21 \%( \pm 1.9)$.

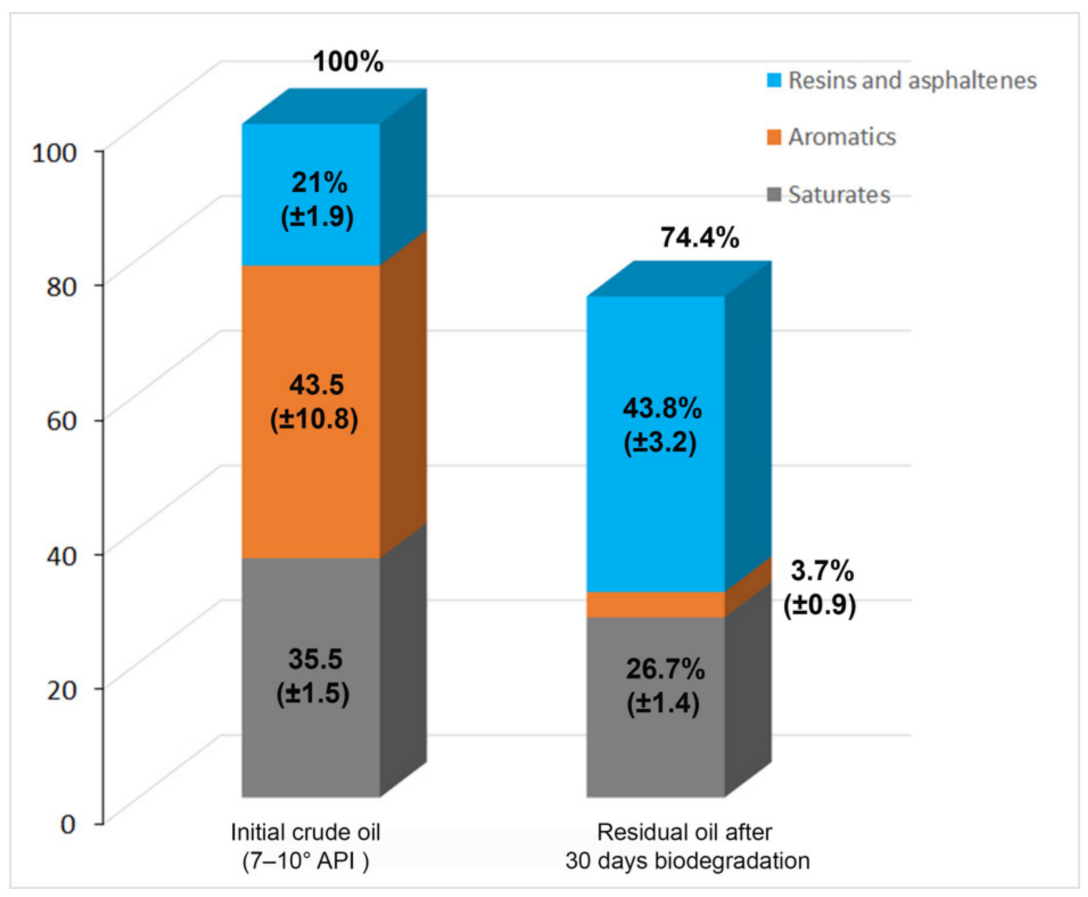

Figure 7. Hydrocarbon degradation after 30 days of growth by Alternaria sp. with extra-heavy crude oil (7-10 $\mathrm{API})$ as the sole source of carbon initial and residual oil compositions. The number on the top of the columns represents the residual oil after biodegradation as a percentage of initial crude oil. The numbers on each column are the percentage of each fraction. The oils were fractionated by the modified SARA procedure to obtain the saturates, aromatics, and polar (resins and asphaltenes) fractions. The total petroleum hydrocarbons were determined by gas chromatography equipped with a flame ionization detector.

According to the chromatograms, Alternaria sp. degraded $25.6 \%( \pm 7.6)$ of the total crude oil (Figure S2). Noteworthy, Alternaria sp. had a higher metabolization of the aromatic fraction, with $91.3 \%( \pm 15.7)$ of degradation of these compounds. It also degraded the saturates fraction by $24.7 \%( \pm 1.0)$. The resin-asphaltene fractions showed an increase of $108 \%( \pm 5.8)$, mainly due to the production of polar molecules. In other words, the composition of the crude oil after biodegradation was $26.7 \%( \pm 1.4)$ of the saturates fraction, $3.7 \%( \pm 0.9)$ of the aromatic fraction, and $43.8 \%( \pm 3.2)$ of polar (resin-asphaltene) fractions (Figure 7). 


\section{Discussion}

Following the 2010 Deepwater Horizon oil spill, fungal strains from oil-soaked sand patties collected from beaches [41] and bacteria from oiled beach sands at Pensacola Beach, FL, USA [42], both sites located in the American EEZ, were identified as potential bioremediation microorganisms. Fungi synthesize a battery of enzymes, including laccases, peroxidases, lytic polysaccharide monooxygenases, and monooxygenase cytochrome P450 that degrade different and complex substrates, including PAHs [43,44]. In addition, isolates from extreme environments have been proven to produce extracellular extremophilic ligninolytic enzymes, which can perform catalytic activities under adverse environments without being denatured [45]. These metabolic capacities and rapid mycelial propagation pose fungi as attractive prospects for bioremediation applications [46]. Notably, marinederived fungi have been recognized as promising bioremediation agents due to their metabolic adaptations to naturally occurring oil sources [47,48]. Yet, they have been scarcely studied for their ability to use recalcitrant elements of HCO and EHCO.

In this study, we showed the ability of Alternaria sp., Penicillium spp., and Stemphylium sp., isolates recovered from deep-sea sediments of the Mexican EEZ of the Gulf of Mexico to grow using $\mathrm{HCO}$ and, most importantly, the ability of Alternaria sp. to grow using EHCO as sole carbon source. Unfortunately, given the nature of the EHCO and the strong attachment of Alternaria sp. mycelium to the EHCO in the glass rod, the quantification of the biomass was not successfully attained. However, at the visible level, one could observe the mycelium of Alternaria sp. only in the cultures supplemented with EHCO (Figure S3). We concluded that the toluene added for protein quantification to get an indirect measurement of the fungal biomass probably interfered with the complete recovery of the mycelium, and the protein content obtained was not an accurate estimate of the actual amount of protein. Although the fungal taxa identified in this study have been previously reported as light and medium crude oil degraders, there are no previous reports of $\mathrm{HCO}$ or EHCO degradation by any of them. Penicillium spp. isolated from diverse polluted environments have been extensively reported as capable of removing a wide array of contaminants, including heavy metals and petroleum hydrocarbons $[49,50]$. Penicillium spp. can efficiently degrade polycyclic aromatic hydrocarbons such as fluorene [51], pyrene [52], and phenanthrene [53]. The Stemphylium sp. has been isolated from petroleum-contaminated soils in Iran [54] and from a Mediterranean marine site after an oil spill, where $C$. halotolerans was recovered as well [55]. P. corylophilum was isolated from ship-breaking yards of Bangladesh and was able to degrade petroleum hydrocarbon [56].

Alternaria spp. have been isolated from terrestrial contaminated zones with evidence of PAH degradation [57], from tar balls with a very limited ability to degrade crude oil [49], and from noncontaminated gardens showing the ability to degrade octane and decane [58]. A. alternata has the capacity to synthesize enzymes related to hydrocarbon degradation, such as manganese peroxidase and lignin peroxidase [59,60]. There is a comparative analysis of the secretome profile of Manganese (II)-Oxidizing [61], as well as a report of lignin peroxidase production [62], and this sets a precedent for the potential degradation capacity of Alternaria sp.

Heavy crude oils contain a high proportion of high molecular weight hydrocarbons and elevated levels of hetero compounds, including sulfur, nitrogen, oxygen, and heavy metals [63]. The typical SARA composition of heavy oils is $4-23 \%$ saturates, $14-32 \%$ aromatics, $27-46 \%$ resins, and $15-43 \%$ asphaltenes [64]. The high concentration of resins and asphaltenes, together with the high concentration of high molecular weight PAHs in EHCO, poses a challenge for biodegradation and bioremediation processes. The chemical nature of the products from hydrocarbon degradation was not analyzed in this study. The composition of crude oil includes several thousands of different hydrocarbons that could potentially represent a carbon source for Alternaria sp. The products resulting from microbial degradation by Alternaria are also a complex mixture of polar compounds hard to resolve by conventional analytical chemistry tools. However, hydrocarbon degradation products' chemical natures have been extensively studied $[65,66]$. Different enzymes 
transform saturated and aromatic hydrocarbons, increasing the relative abundance of polar fractions. Various pathways, such as terminal oxidation, subterminal oxidation, $\omega$-oxidation, and $\beta$-oxidation, are involved in the degradation of aliphatic hydrocarbons. The initial alkane oxidation results in the formation of an alcohol, which can then be metabolized by the $\beta$-oxidation pathway of fatty acids. On the other hand, fungi's initial oxidation of aromatic hydrocarbons is mediated by monooxygenases forming a trans-diol. The benzene ring is then cleaved in different ways by appropriate enzymes leading to the formation of central intermediates, which are further converted to tricarboxylic acid (TCA) cycle intermediates. Finally, cyclic alkanes are converted to cyclic alcohols and dehydrogenated to ketones by an oxidase system. Then, a monooxygenase system forms lactonates, and a lactone hydrolase finally opens the ring.

Our study proved that Alternaria sp. has a great affinity for the aromatic fraction of EHCO, showing an extensive transformation of $91.3 \%$ of this fraction. The aromatic fraction that was transformed by Alternaria sp. to more polar compounds migrated to the resin-asphaltene fraction in the degraded hydrocarbons, as suggested by the percentage increase of this fraction. Despite this increase, it has been previously well-established that the polar compounds appearing in the resin-asphaltene fraction as a result of the biodegradation of saturates and, especially, of the aromatic fraction, are more biodegradable than the original hydrocarbons, and they can be more accessible for degradation by other microorganisms $[67,68]$.

The station N2 (Perdido region), from where Alternaria sp. was isolated, did not display any remarkable difference in salinity, temperature, or dissolved oxygen concentration compared with the rest of the stations (Supplementary Table S2). The Gulf of Mexico has a two-layer system; the upper layer (above $800-1000 \mathrm{~m}$ ) is highly regulated by the Loop Current and its associated eddies (LCEs) entering the Gulf of Mexico through the Yucatan Channel [69]. The river discharges, the temperature variation, and the freshwater input do not impact the salinity or temperature beyond the upper $100 \mathrm{~m}$ of the water column [70]. Consequently, the main driver in the hydrographic conditions in the GoM where the sediments samples were taken was the local presence of LCEs [70]. Regardless of the wide distribution of the sites sampled in the Gulf of Mexico, it is not possible to recognize a difference between the Perdido and Coatzacoalcos Stations. Temperature and dissolved oxygen variation respond mainly to the depth of the sediments, and there is an insignificant variation in the salinity in all the stations.

Recent estimations report that unconventional oil reserves, which include $\mathrm{HCO}$, EHCO, and bitumen, could exceed six trillion barrels [71]. The ineludible extraction of these reservoirs will inevitably produce oil spills. It is essential to explore native fungal microorganisms capable of degrading HCO and, especially, EHCO to mitigate the environmental impact of accidental petroleum spills. Offshore oil spills are of tremendous concern due to their potential impact on the economy and especially on ecological systems [72]. The successful bioremediation of marine oil spills has been reported [73]. Among the bioremediation strategies, biostimulation is an in situ technology that involves the introduction of indigenous (obtained from the contaminated site) or exogenous hydrocarbonoclastic microorganisms to a polluted site to enhance microbial degradation at the site. Many degradation studies are focused on water column degradation, and no attention has been given to sediment oil degradation. Oil biodegradation in sediments is significant for the heavy fractions of oil, which tend to settle after the oil spill. In addition, the sediment environmental conditions are different such as oxygen and nutrient concentrations. There are nevertheless some challenges associated with bioremediation of spilled petroleum [74], including: (i) the resistance of heavy fractions, especially asphaltenes and high molar mass polycyclic aromatic hydrocarbons, to degradation. Thus, it seems crucial to have microbial strains able to perform the biodegradation of heavy and extra-heavy oils such as Alternaria sp. isolated and characterized in this work; (ii) eutrophication caused by biostimulation. Seawater is characterized by the low nitrogen and phosphorous concentrations that are limiting factors for oil degradation. The use of oleophilic fertilizers seems to be an effec- 
tive nutrient type to be applied in marine environments to prevent eutrophication; (iii) unsustainability of bioaugmentation in the field. This can be reduced using well-adapted microorganisms, like, for instance, those adapted to sediment conditions. In addition, the encapsulation of the microorganism can protect it in the new environmental conditions; (iv) poor bioavailability of spilled petroleum. Oil biodegradation takes place at the oilwater interphase. Therefore, the widely used oil dispersion or solubilization by adding chemical or biological surfactants enhances biodegradation. However, the chemical agents could be potentially toxic to the environment; and (v) oil biodegradation inefficiency in semi-anoxic environments. As mentioned before, in deep sediments, there is a low oxygen concentration. It is also important to have microorganisms isolated from similar sediment conditions, such as the Alternaria sp. isolated and characterized in this work.

Considering all the above, microorganisms that, like Alternaria sp., are capable of degrading some of the heavier and more recalcitrant components of these crude oils can be good candidates for further studies testing different environmental conditions in order to assess their use for bioremediation in the event of an oil spill.

Supplementary Materials: The following are available online at https:/ /www.mdpi.com/article/10 .3390/app11136090/s1: Table S1: Geolocalization and data of stations sampled in the Gulf of Mexico. Table S2: Sampling stations and locations from where the fungal strains were isolated. Table S3: Reference DNA sequences of the ITS rDNA, 18S and $\beta$-tubulin markers used in the phylogenetic analyses. Figure S1: Protein content (average of three replicates) of Penicillium sp. 1 (A) and Penicillium sp. 2 (B) grown under different light crude oil concentrations. Figure S2: Chromatograms of whole extra-heavy crude oil and its saturates, aromatics and polars (SAP) fractions. Figure S3: Alternaria sp. grown with $(\mathrm{B}, \mathrm{D})$ or without $(\mathrm{A}, \mathrm{C}) 0.5 \% \mathrm{w} / \mathrm{v}$ of extra-heavy crude oil as sole carbon source after a month of incubation.

Author Contributions: Conceptualization, M.R.; methodology, L.R.-H., M.D.C.-L., P.V. and I.B.-G.; investigation, L.R.-H.; writing—original draft preparation, L.R.-H.; writing—review and editing, M.R., P.V. and R.V.-D.; formal analysis, L.R.-H.; supervision, M.R. and R.V.-D.; project administration, M.R.; and funding acquisition, M.R. All authors have read and agreed to the published version of the manuscript.

Funding: This research was funded by the National Council of Science and Technology of MexicoMexican Ministry of Energy-Hydrocarbon Trust, project 201441. This is a contribution of the Gulf of Mexico Research Consortium (CIGoM). LRH was supported by CONACYT doctoral fellowship 259695.

Institutional Review Board Statement: Not applicable.

Informed Consent Statement: Not applicable.

Data Availability Statement: The data is contained within the article and supplementary material.

Acknowledgments: We thank Karla Sidon for collecting the samples and Lluvia Vargas-Gastélum for carefully reading the manuscript. Microscopy analyses were carried out at the National Laboratory of Advanced Microscopy of CICESE (LNMA) and the Department of Optics of CICESE. We are grateful to Diego Delgado, Fabian Cordero, Pilar Sánchez-Saavedra, and Juan Manuel Martínez for their technical support.

Conflicts of Interest: The authors declare that they have no known competing financial interests or personal relationships that could have appeared to influence the work reported in this paper. 


$\begin{array}{ll}\text { Abbreviations } & \\ \text { Gulf of Mexico } & \text { GoM } \\ \text { Heavy Crude Oil } & \text { HCO } \\ \text { Extra-heavy Crude Oil } & \text { EHCO } \\ \text { Polycyclic Aromatic Hydrocarbons } & \text { PAHs } \\ \text { Metagenomics Campaign } & \text { MET-II } \\ \text { Potato Dextrose Agar } & \text { PDA } \\ \text { Differential Interference Contrast } & \text { DIC } \\ \text { Internal Transcribed Spacer } & \text { ITS } \\ \beta \text {-tubulin gene } & \text { benA } \\ \text { Maximum Likelihood } & \text { ML } \\ \text { Maximum Composite Likelihood } & \text { MCL } \\ \text { American Petroleum Institute } & \text { API } \\ \text { Total Petroleum Hydrocarbons } & \text { TPH } \\ \text { Flame Ionization Detector } & \text { FID } \\ \text { Scanning Electron Microscopy } & \text { SEM } \\ \text { Saturate, Aromatic and Polar } & \text { SAP } \\ \text { Economic Exclusive Zone } & \text { EZZ } \\ \text { Gulf of Mexico Research Consortium } & \text { CIGoM }\end{array}$

\section{References}

1. Matsuo, Y.; Yanagisawa, A.; Yamashita, Y. A global energy outlook to 2035 with strategic considerations for Asia and Middle East energy supply and demand interdependencies. Energy Strat. Rev. 2013, 2, 79-91. [CrossRef]

2. British Petroleum Company. BP Energy Outlook 2035; British Petroleum Company: London, UK, 2015.

3. Kuppusamy, S.; Maddela, N.R.; Megharaj, M.; Venkateswarlu, K. Total Petroleum Hydrocarbons. Environ. Fate Toxic. Remediat. 2020. [CrossRef]

4. Guo, K.; Li, H.; Yu, Z. In situ heavy and extra-heavy oil recovery: A review. Fuel 2016, 185, 886-902. [CrossRef]

5. Demirbas, A.; Bafail, A.; Nizami, A.-S. Heavy oil upgrading: Unlocking the future fuel supply. Pet. Sci. Technol. 2016, 34, 303-308. [CrossRef]

6. Covert, T.; Greenstone, M.; Knittel, C.R. Will We Ever Stop Using Fossil Fuels? J. Econ. Perspect. 2016, 30, 117-138. [CrossRef]

7. He, L.; Lin, F.; Li, X.; Sui, H.; Xu, Z. Interfacial sciences in unconventional petroleum production: From fundamentals to ap-plications. Chem. Soc. Rev. 2015, 44, 5446-5494. [CrossRef]

8. Farrington, J.W. Need to update human health risk assessment protocols for polycyclic aromatic hydrocarbons in seafood after oil spills. Mar. Pollut. Bull. 2020, 150, 110744. [CrossRef] [PubMed]

9. Warnock, A.M.; Hagen, S.C.; Passeri, D.L. Marine Tar Residues: A Review. Water Air Soil Pollut. 2015, 226, 1-24. [CrossRef]

10. Zhang, B.; Matchinski, E.J.; Chen, B.; Ye, X.; Jing, L.; Lee, K. Marine Oil Spills—Oil Pollution, Sources and Effects. In World Seas: An Environmental Evaluation; Elsevier BV: Amsterdam, The Netherlands, 2019; pp. 391-406.

11. Harwell, M.A.; Gentile, J.H. Ecological significance of residual exposures and effects from the Exxon Valdez oil spill. Integr. Environ. Assess. Manag. 2006, 2, 204. [CrossRef]

12. Mei, H.; Yin, Y. Studies on marine oil spills and their ecological damage. J. Ocean. Univ. China 2009, 8, 312-316. [CrossRef]

13. Das, N.; Chandran, P. Microbial Degradation of Petroleum Hydrocarbon Contaminants: An Overview. Biotechnol. Res. Int. 2011, 2011, 1-13. [CrossRef]

14. Frias-Lopez, J.; Shi, Y.; Tyson, G.; Coleman, M.; Schuster, S.C.; Chisholm, S.W.; DeLong, E.F. Microbial community gene expression in ocean surface waters. Proc. Natl. Acad. Sci. USA 2008, 105, 3805-3810. [CrossRef] [PubMed]

15. Al-Hawash, A.B.; Dragh, M.A.; Li, S.; Alhujaily, A.; Abbood, H.A.; Zhang, X.; Ma, F. Principles of microbial degradation of petroleum hydrocarbons in the environment. Egypt. J. Aquat. Res. 2018, 44, 71-76. [CrossRef]

16. Naranjo-Briceño, L.; Pernía, B.; Perdomo, T.; González, M.; Inojosa, Y.; De Sisto, Á.; Urbina, H.; León, V. Potential role of extremophilic hydrocarbonoclastic fungi for extra-heavy crude oil bioconversion and the sustainable development of the petroleum industry. In Fungi in Extreme Environments: Ecological Role and Biotechnological Significance; Tiquia-Arashiro, S.M., Grube, M., Eds.; Springer: Cham, Switzerland, 2019; pp. 559-586. [CrossRef]

17. Uribe-Alvarez, C.; Ayala, M.; Perezgasga, L.; Naranjo, L.; Urbina, H.; Vazquez-Duhalt, R. First evidence of mineralization of petroleum asphaltenes by a strain of Neosartorya fischeri. Microb. Biotechnol. 2011, 4, 663-672. [CrossRef]

18. López, E.L.H.; Perezgasga, L.; Huerta-Saquero, A.; Mouriño-Pérez, R.R.; Vazquez-Duhalt, R. Biotransformation of petroleum asphaltenes and high molecular weight polycyclic aromatic hydrocarbons by Neosartorya fischeri. Environ. Sci. Pollut. Res. 2016, 23, 10773-10784. [CrossRef]

19. Naranjo-Briceño, L.; Pernia, B.; Guerra, M.; Demey, J.R.; De Sisto, Á.; Inojosa, Y.; Gonzalez, M.; Fusella, E.; Freites, M.; Yegres, F. Potential role of oxidative exoenzymes of the extremophilic fungus Pestalotiopsis palmarum BM-04 in biotransformation of extra-heavy crude oil. Microb. Biotechnol. 2013, 6, 720-730. [CrossRef] 
20. Chaillan, F.; Le Flèche, A.; Bury, E.; Phantavong, Y.-H.; Grimont, P.; Saliot, A.; Oudot, J. Identification and biodegradation potential of tropical aerobic hydrocarbon-degrading microorganisms. Res. Microbiol. 2004, 155, 587-595. [CrossRef]

21. Ayala, M.; López, E.L.H.; Perezgasga, L.; Vazquez-Duhalt, R. Reduced coke formation and aromaticity due to chloroperoxidasecatalyzed transformation of asphaltenes from Maya crude oil. Fuel 2012, 92, 245-249. [CrossRef]

22. Pourfakhraei, E.; Badraghi, J.; Mamashli, F.; Nazari, M.; Saboury, A.A. Biodegradation of asphaltene and petroleum compounds by a highly potent Daedaleopsi ssp. J. Basic Microbiol. 2018, 58, 609-622. [CrossRef] [PubMed]

23. Murawski, S.A.; Hollander, D.J.; Gilbert, S.; Gracia, A. Deepwater Oil and Gas Production in the Gulf of Mexico and Related Global Trends. In Scenarios and Responses to Future Deep Oil Spills; Springer: Berlin/Heidelberg, Germany, 2020 ; pp. 16-32.

24. Velez, P.; Gasca-Pineda, J.; Riquelme, M. Cultivable fungi from deep-sea oil reserves in the Gulf of Mexico: Genetic signatures in response to hydrocarbons. Mar. Environ. Res. 2020, 153, 104816. [CrossRef] [PubMed]

25. Hickey, P.C.; Swift, S.R.; Roca, M.G.; Read, N.D. Live-cell imaging of filamentous fungi using vital fluorescent dyes and con-focal microscopy. Methods Microbiol. 2004, 34, 63-87. [CrossRef]

26. Kohlmeyer, J.; Kohlmeyer, E. Marine Mycology: The Higher Fungi; Academic Press: Cambridge, MA, USA, 1979.

27. Lücking, R.; Aime, M.C.; Robbertse, B.; Miller, A.N.; Ariyawansa, H.A.; Aoki, T.; Cardinali, G.; Crous, P.W.; Druzhinina, I.S.; Geiser, D.M.; et al. Unambiguous identification of fungi: Where do we stand and how accurate and precise is fungal DNA barcoding? IMA Fungus 2020, 11, 1-32. [CrossRef] [PubMed]

28. Gardes, M.; Bruns, T.D. ITS primers with enhanced specificity for basidiomycetes-Application to the identification of mycorrhizae and rusts. Mol. Ecol. 1993, 2, 113-118. [CrossRef]

29. White, T.; Bruns, T.; Lee, S.; Taylor, J.; Innis, M.; Gelfand, D.; Sninsky, J. Amplification and direct sequencing of fungal ribo-somal RNA genes for phylogenetics. In PCR Protocols: A Guide to Methods and Applications; Academic Press: Cambridge, MA, USA, 1990.

30. Gargas, A.; Taylor, J.W. Polymerase chain reaction (PCR) primers for amplifying and sequencing nuclear $18 \mathrm{~S}$ rDNA from lichenized fungi. Mycologia 1992, 84, 589-592. [CrossRef]

31. Glass, N.L.; Donaldson, G.C. Development of primer sets designed for use with the PCR to amplify conserved genes from filamentous ascomycetes. Appl. Environ. Microbiol. 1995, 61, 1323-1330. [CrossRef]

32. Ewing, B.; Hillier, L.; Wendl, M.C.; Green, P. Base-Calling of Automated Sequencer Traces UsingPhred. I. Accuracy Assessment. Genome Res. 1998, 8, 175-185. [CrossRef]

33. Ewing, B.; Green, P. Base-calling of automated sequencer traces using Phred. II. Error probabilities. Genome Res. 1998, 8, 186-194. [CrossRef] [PubMed]

34. Gordon, D.; Desmarais, C.; Green, P. Automated Finishing with Autofinish. Genome Res. 2001, 11, 614-625. [CrossRef] [PubMed]

35. Okonechnikov, K.; Golosova, O.; Fursov, M. The UGENE Team. Unipro UGENE: A unified bioinformatics toolkit. Bioinformatics 2012, 28, 1166-1167. [CrossRef]

36. Edgar, R.C. MUSCLE: Multiple sequence alignment with high accuracy and high throughput. Nucleic Acids Res. 2004, 32, 1792-1797. [CrossRef] [PubMed]

37. Stecher, G.; Tamura, K.; Kumar, S. Molecular Evolutionary Genetics Analysis (MEGA) for macOS. Mol. Biol. Evol. 2020, 37, 1237-1239. [CrossRef] [PubMed]

38. Kumar, S.; Stecher, G.; Li, M.; Knyaz, C.; Tamura, K. MEGA X: Molecular evolutionary genetics analysis across computing platforms. Mol. Biol. Evol. 2018, 35, 1547-1549. [CrossRef]

39. Kimura, M. A simple method for estimating evolutionary rates of base substitutions through comparative studies of nucleotide sequences. J. Mol. Evol. 1980, 16, 111-120. [CrossRef]

40. Abalos, A.; Viñas, M.; Sabate, J.; Manresa, A.; Solanas, A. Enhanced Biodegradation of Casablanca Crude Oil by A Microbial Consortium in Presence of a Rhamnolipid Produced by Pseudomonas Aeruginosa AT10. Biodegradation 2004, 15, 249-260. [CrossRef] [PubMed]

41. Simister, R.; Poutasse, C.; Thurston, A.; Reeve, J.; Baker, M.; White, H. Degradation of oil by fungi isolated from Gulf of Mexico beaches. Mar. Pollut. Bull. 2015, 100, 327-333. [CrossRef] [PubMed]

42. Kostka, J.E.; Prakash, O.; Overholt, W.A.; Green, S.; Freyer, G.; Canion, A.; Delgardio, J.; Norton, N.; Hazen, T.C.; Huettel, M. Hydrocarbon-Degrading Bacteria and the Bacterial Community Response in Gulf of Mexico Beach Sands Impacted by the Deepwater Horizon Oil Spill. Appl. Environ. Microbiol. 2011, 77, 7962-7974. [CrossRef]

43. Otero-Blanca, A.; Folch-Mallol, J.L.; Lira-Ruan, V.; del Rayo Sánchez-Carbente, M.; Batista-García, R.A. Phytoremediation and Fungi: An Underexplored Binomial. In Approaches in Bioremediation; Springer Science and Business Media LLC: Berlin/Heidelberg, Germany, 2018; pp. 79-95.

44. Deshmukh, R.; Khardenavis, A.A.; Purohit, H.J. Diverse Metabolic Capacities of Fungi for Bioremediation. Indian J. Microbiol. 2016, 56, 247-264. [CrossRef]

45. Chandra, R.; Kumar, V.; Yadav, S. Extremophilic Ligninolytic Enzymes. In Extremophilic Enzymatic Processing of Lignocellulosic Feedstocks to Bioenergy; Springer Science and Business Media LLC: Berlin/Heidelberg, Germany, 2017; pp. 115-154.

46. Vidali, M. Bioremediation. An overview. Pure Appl. Chem. 2001, 73, 1163-1172. [CrossRef]

47. Kumar, R.; Kaur, A. Oil spill removal by mycoremediation. In Microbial Action on Hydrocarbons; Kumar, V., Kumar, M., Pra-sad, R., Eds.; Springer: Singapore, 2018; pp. 505-526. [CrossRef]

48. Kvenvolden, K.A.; Cooper, C.K. Natural seepage of crude oil into the marine environment. Geo-Marine Lett. 2003, 23, 140-146. [CrossRef] 
49. Elshafie, A.; Alkindi, A.Y.; Al-Busaidi, S.; Bakheit, C.; Albahry, S. Biodegradation of crude oil and n-alkanes by fungi isolated from Oman. Mar. Pollut. Bull. 2007, 54, 1692-1696. [CrossRef]

50. Singh, H. Mycoremediation: Fungal Bioremediation; John Wiley \& Sons: Hoboken, NJ, USA, 2006.

51. Garon, D.; Sage, L.; Seigle-Murandi, F. Effects of fungal bioaugmentation and cyclodextrin amendment on fluorene degrada-tion in soil slurry. Biodegradation 2004, 15, 1-8. [CrossRef] [PubMed]

52. Saraswathy, A.; Hallberg, R. Mycelial pellet formation by Penicillium ochrochloron species due to exposure to pyrene. Microbiol. Res. 2005, 160, 375-383. [CrossRef]

53. Melendez-Estrada, J.; Amezcua-Allieri, M.A.; Alvarez, P.; Rodríguez-Vázquez, R. Phenanthrene Removal byPenicillium frequentansGrown on a Solid-State Culture: Effect of Oxygen Concentration. Environ. Technol. 2006, 27, 1073-1080. [CrossRef]

54. Mohammadian, E.; Arzanlou, M.; Babai-Ahari, A. Diversity of culturable fungi inhabiting petroleum-contaminated soils in Southern Iran. Antonie van Leeuwenhoek 2017, 110, 903-923. [CrossRef] [PubMed]

55. Bovio, E.; Gnavi, G.; Prigione, V.; Spina, F.; Denaro, R.; Yakimov, M.; Calogero, R.; Crisafi, F.; Varese, G.C. The culturable mycobiota of a Mediterranean marine site after an oil spill: Isolation, identification and potential application in bioremediation. Sci. Total Environ. 2017, 576, 310-318. [CrossRef] [PubMed]

56. Dhar, K.; Dutta, S.; Anwar, M.N. Biodegradation of petroleum hydrocarbon by indigenous fungi isolated from ship breaking yards of Bangladesh. Int. Res. J. Biol. Sci. 2014, 3, 22-30.

57. Balaji, V.; Arulazhagan, P.; Ebenezer, P. Enzymatic bioremediation of polyaromatic hydrocarbons by fungal consortia en-riched from petroleum contaminated soil and oil seeds. J. Environ. Biol. 2014, 35, 521-529. [PubMed]

58. Loretta, O.O.; Samuel, O.; Johnson, G.H.; Emmanuel, S. Comparative Studies on the Biodegradation of Crude Oil-polluted Soil by Pseudomonas aeruginosa and Alternaria Species Isolated from Unpolluted Soil. Microbiol. Res. J. Int. 2017, 19, 1-10. [CrossRef]

59. Ali, M.I.; Khalil, N.M.; Abd El-Ghany, M.N. Biodegradation of some polycyclic aromatic hydrocarbons by Aspergillus terreus. Afr. J. Microbiol. Res. 2012, 6, 3783-3790.

60. Vazquez-Duhalt, R.; Westlake, D.W.S.; Fedorak, P.M. Lignin peroxidase oxidation of aromatic compounds in systems con-taining organic solvents. Appl. Environ. Microbiol. 1994, 60, 459-466. [CrossRef] [PubMed]

61. Zeiner, C.A.; Purvine, S.; Zink, E.M.; Paša-Tolić, L.; Chaput, D.L.; Haridas, S.; Wu, S.; LaButti, K.; Grigoriev, I.V.; Henrissat, B.; et al. Comparative Analysis of Secretome Profiles of Manganese(II)-Oxidizing Ascomycete Fungi. PLoS ONE 2016, 11, e0157844. [CrossRef]

62. Sharma, A.; Aggarwal, N.K.; Yadav, A. First Report of Lignin Peroxidase Production from Alternaria alternata ANF238 Isolated from Rotten Wood Sample. Bioeng. Biosci. 2016, 4, 76-87. [CrossRef]

63. Speight, J.G. The Chemistry and Technology of Petroleum; Marcel Decker: New York, NY, USA, 1999.

64. Hinkle, A.; Shin, E.-J.; Liberatore, M.W.; Herring, A.M.; Batzle, M. Correlating the chemical and physical properties of a set of heavy oils from around the world. Fuel 2008, 87, 3065-3070. [CrossRef]

65. Varjani, S.J. Microbial degradation of petroleum hydrocarbons. Bioresour. Technol. 2017, 223, 277-286. [CrossRef] [PubMed]

66. Van Hamme, J.D.; Singh, A.; Ward, O.P. Recent Advances in Petroleum Microbiology. Microbiol. Mol. Biol. Rev. 2003, 67, 503-549. [CrossRef] [PubMed]

67. Meulenberg, R.; Rijnaarts, H.H.; Doddema, H.J.; A Field, J. Partially oxidized polycyclic aromatic hydrocarbons show an increased bioavailability and biodegradability. FEMS Microbiol. Lett. 2006, 152, 45-49. [CrossRef]

68. Kulik, N.; Goi, A.; Trapido, M.; Tuhkanen, T. Degradation of polycyclic aromatic hydrocarbons by combined chemical preoxidation and bioremediation in creosote contaminated soil. J. Environ. Manag. 2006, 78, 382-391. [CrossRef] [PubMed]

69. Hamilton, P. Topographic Rossby waves in the Gulf of Mexico. Prog. Oceanogr. 2009, 82, 1-31. [CrossRef]

70. Portela, E.; Tenreiro, M.; Pallàs-Sanz, E.; Meunier, T.; Ruiz-Angulo, A.; Sosa-Gutiérrez, R.; Cusí, S. Hydrography of the central and western Gulf of Mexico. J. Geophys. Res. Ocean. 2018, 123, 5134-5149. [CrossRef]

71. Alboudwarej, H.; Felix, J.; Taylor, S.; Badry, R.; Bremner, C.; Brough, B.; Palmer, D.; Pattisson, K.; Beshry, M.; Krawchuk, P.; et al. Highlighting heavy oil. Schlumberger Oilfield Rev. Summer 2006, 18, 34-53.

72. Kingston, P. Long-term environmental impact of oil spills. Splill Sci. Technol. Bull. 2002, 7, 53-61. [CrossRef]

73. Atlas, R.M.; Hazen, T.C. Oil Biodegradation and Bioremediation: A Tale of the Two Worst Spills in U.S. History. Environ. Sci. Technol. 2011, 45, 6709-6715. [CrossRef] [PubMed]

74. Macaulay, B.M.; Rees, D. Bioremediation of oil spills: A review of challenges for research advancement. Ann. Environ. Sci. 2014, 8, 9-37. 